\title{
PLANS FOR MONITORING FOOD AND NUTRITION IN NSW
}

Beth Stickney, KarenWebb and Vicki Flood Department of Public Health and Community Medicine University of Sydney

\section{Moira Hewitt}

Department of Public Health and Community Medicine University of Sydney and Master of Applied Epidemiology Program, National Centre for Epidemiology and Population. Health, Canberra

-his article describes the NSW Food and Nutrition

Monitoring Plan, which makes recommendations for meeting currently unmet information needs in $\mathrm{NSW}^{1}$. Goals were to:

- provide timely, high-quality, accessible and appropriate data for decision-making about nutrition policy and programs; and complement national, State and local monitoring programs.

Recommendations are based on principles of effective monitoring and surveillance $\mathrm{e}^{2.8}$ and relate to:

indicators for nutrition monitoring in NSW; appropriate tools and mechanisms for collection, analysis, reporting, feedback and dissemination of data on chosen indicators; and appropriate roles for the various agencies and levels of government in relation to data collection, analysis, and dissemination.

\section{WHAT IS FOOD AND NUTRITION MONITORING?}

The terms "monitoring" and "surveillance" have been defined in many ways and are sometimes used. interchangeably ${ }^{1-3}$. For the purpose of our project, nutrition monitoring is defined as: "An ongoing description of foodand nutrition-related issues useful for decision-making that will lead to improvements in the nutritional status of populations".

\section{WHY IS FOOD AND NUTRITION MONITORING NEEDED IN NSW?}

Up-to-date information is needed to make good management decisions about nutrition policies and programs ${ }^{9,10}$.

Monitoring systems can contribute valuable information for meeting these requirements: tracking progress towards goals and targets; assessing the impact of the effort to improve nutrition; comparing population subgroups for nutrition and dietary problems and trends in these; and planning and improving food and nutrition policies, programs and services ${ }^{1: 3,710}$. Food and Nutrition in NSW highlighted gaps in information and the lack of comparability of methods used to measure common food and nutrition indicators ${ }^{11}$.

National nutrition monitoring plans were considered carefully in the preparation of the NSW strategy. However, a planned approach to monitoring at the State level is needed to ensure that State priorities are met, that local monitoring activities relevant to these priorities are well coordinated, and that State monitoring complements national and local monitoring.

\section{WHO IS THE PLAN FOR?}

Health professionals throughout NSW were consulted, so that users' needs would be met. Participants identified the most important issues and indicators for Statewide monitoring and how they use nutrition information. This consultation process, with an extensive literature review and liaison with national groups, contributed to the selection of components of the plan for food and nutrition monitoring in NSW. We identified the following potential users of the plan:

1. NSW Health Department: Food and Nutrition Unit, Centre for Clinical Policy and Practice, Epidemiology and Surveillance Branch, Centre for Disease Prevention and Health Promotion and the Chief Health Officer.

2. NSW Area Health Service personnel: Area planners, Area Health Promotion and Public Health Unit personnel, community nutritionists, health outcomes councils.

3. Other potential suppliers and users of nutrition information, including: Commonwealth agencies, researchers and public health academics, nutrition-related non-government organisations and other State governments.

\section{WHAT ARE THE PRIORITIES FOR FOOD AND NUTRITION MONITORING IN NSW?}

An effective monitoring system cannot meet all information needs. The NSW plan focuses on information that is either: 1. perceived as a priority for health service managers and policy makers in food and nutrition in NSW; or 2. fills an important gap in information, as identified by those interested in population nutrition. Recommendations are made for collection of information only where valid and practicable population-oriented measurements are available. Needs for nutrition information from a monitoring system (identified by consultation) are wideranging, and include: weight status, growth of children, intakes of particular nutrients (fat, iron, calcium, folate), physical and biochemical risk factors for diet-related disease (lipids, blood pressure, iron, folate), food habits (core food groups, breast-feeding and other infant feeding practices, meal patterns, high-fat and low-fat food consumption, salt habits, alcoholic beverages and qualitative aspects of dietary change), food security, and aspects of the food system or food environment.

Concrete plans for monitoring were developed for only a few of these issues, including weight status, fat intake, selected food habits and food security. However, recommendations have been made on the next steps to be taken in developing and testing the methods required to meet other information needs.

\section{COMPONENTS OF THE PLAN}

Short dietary survey modules: Short sets of questions suitable for population-based health surveys (including the NSW Health Survey) have been compiled. These measure selected aspects of dietary behaviour (such as intake of fruit, vegetables, breads and cereals), habits related to intakes of fat, saturated fat, calcium and iron, breast-feeding and other infant feeding practices, food security, barriers to dietary change, and meal patterns. The dietary questions have been researched extensively and the rationale for inclusion of each is given. This document is described in more detail in an accompanying article in this issue ( $\mathrm{p} 44$ ). 
A guide for monitoring overweight and obesity in NSW: This includes recommendations on which anthropometric indicators should be measured in population health surveys and standards for classifying weight status consistent with recent World Health Organisation recommendations and those drafted for National Monitoring of Overweight and Obesity in Australia. Options for obtaining data about population subgroups of interest are outlined, such as anthropometric measurements in population- and school-based surveys and longitudinal studies of selected groups. Use of the guide is recommended for designing and modifying such surveys and studies. Its use would also improve the availability of comparable information on trends in overweight and obesity, particularly among groups for which information is limited or unavailable (for example, school children, adolescents and older people). The guide is described in more detail in the accompanying article (p 46).

\section{A protocol for a validity study of self-reported weights} and heights: A validity study is proposed for monitoring the prevalence of overweight and obesity on the basis of selfreported weights and heights in the NSW Health Survey. The error associated with self-reported weight and height data differs among population groups, over time, and with the mode of administration of questions (telephone questions, face-to-face interviews, or mailed questionnaires). Estimates of the error in self-reported data (as determined by measured heights and weights) are therefore required for the NSW Health Survey.

\section{Specifications of NSW requirements from the} National Nutrition Survey (NSW data): Detailed tables and specifications for information required from the 1995 National Nutrition Survey have been outlined, including recommendations for analysis, presentation and dissemination of NSW-related data. Information relating to current nutrition goals and strategies in NSW and to the priorities identified by health workers for nutrition data guided the development of specifications.

\section{Update of sections of the food and nutrition} catalogue for NSW: Recommendations have been made for the production and dissemination of the first update of Food and Nutrition in NSW: a catalogue of data ${ }^{11}$. This catalogue provides a comprehensive source of data and is widely used by health and nutrition professionals in NSW.

A kit for monitoring school canteens: The kit includes methods and tools for the assessment and monitoring of canteen policies, practices and the availability of healthier food choices. Detailed instructions are provided for health personnel who work with school canteens. Use of the kit would improve the comparability of the substantial amount of information now collected about school canteens. The kit is described more fully in an accompanying article ( $p 49$ ).

Other activities: Recommendations have been made about other monitoring activities that require development, implementation or support, including:

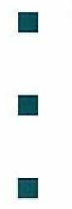

identifying and monitoring indicators of the food "environment";

developing short questions for population-based surveys of selected ethnic groups and children; monitoring growth of children in selected population subgroups;

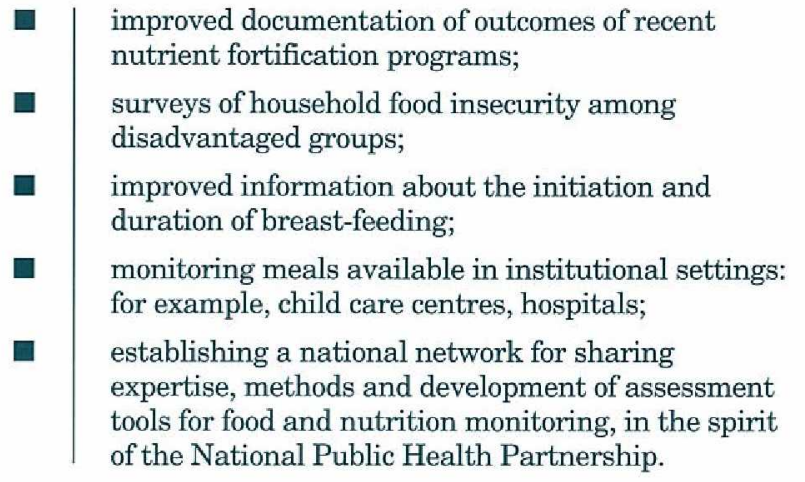

\section{STATUS OF THE PLAN}

Several aspects of the plan have been implemented: for example, selected short modules in the current round of the NSW Health Survey. The forthcoming Chief Health Officer's report (1997) has included the information recommended in the plan and the validation study of selfreported heights and weights has begun. Other components, such as the school canteen kit, are awaiting approval prior to wide dissemination. Mechanisms to improve the cohesiveness and continuity of the nutrition monitoring efforts in NSW are being considered by NSW Health.

\section{ACKNOWLEDGEMENTS}

We thank the many health personnel in NSW who participated in our consultations, and members of the advisory committee and consultants for helpful directionsetting advice throughout the project:

\section{Advisory Committee}

Edwina Macoun, Louisa Jorm, Glenn Close, Bill Porter, Andrew Hahn

\section{Consultants}

Stephen Leeder, Geoffrey Marks, Ingrid Coles-Rutishauser, Dorothy Mackerras, Alan Shiell, Ross Lazarus, Louise Baur, Bill Schofield, Fiona Blyth, Annette Dobson

\footnotetext{
1. Stickney B, Webb K, Flood V, Hewitt M. The NSW Food and Nutrition Monitoring Plan. NSW Health Department, 1997.

2. Mason JB, Habicht J-P, Tabatabai H, Valverde V. Nutritional surveillance, Geneva: WHO, 1984.

3. Marks GC. Nutritional surveillance in Australia: a case of groping in the dark? Aust J Public Health 1991; 15(4):277-280.

4. Coles-Rutishauser IHE, Lester IH. Plan for a national food and nutrition monitoring program. Food and Nutrition Monitoring Unit

Working Paper No 95.2, Canberra: Australian Institute of Health and Welfare, 1995

5. Morbidity and Mortality Weekly Report. Guidelines for evaluating surveillance systems. MMWR, Centers for Disease Control 1988; 37(S-5):1-18.

6. Thacker SB, Stroup DF. Future Directions for Comprehensive Public Health Surveillance and Health Information Systems in the United States. Am J Epidemiol 1994; 140(5):383-397.

7. Lester IH. Australia's Food and Nutrition. Canberra: AGPS, 1994. 8. Life Sciences Research Office. Third Report on Nutrition Monitoring in the United States. Washington DC: US Government Printing Office, 1995.

9. Habicht J-P, Mason J. Nutritional Surveillance: Principles and Practice. In: McLaren DS, ed. Nutrition in the Community. John Wiley and Sons Ltd, 1983.

10. Pelletier DL, Shrimpton R. The role of information in the planning, management and evaluation of community nutrition programs. Health Policy and Planning 1994; 9(2):171-184.

11. Stickney B, Webb KL, Campbell C, Moore AR. Food and Nutrition in New South Wales: a catalogue of data. Sydney NSW Health Department,
} 1994. ISBN 073103658 1. State Health Publication No. (HP) 94-066. 